\title{
Life-history variation in three coexisting species of carnid flies (Diptera: Carnidae), Carnus hemapterus, Hemeromyia anthracina and Hemeromyia longirostris
}

\author{
Francisco VALERA ${ }^{1}$, Manuel MARTíN-VIVALDI² and Miguel CARLES-TOLRÁ ${ }^{3}$ \\ ${ }^{1}$ Estación Experimental de Zonas Áridas (Consejo Superior de Investigaciones Científicas), General Segura 1, E-04001 Almería, \\ Spain; e-mail: pvalera@eeza.csic.es \\ ${ }^{2}$ Departamento de Biología Animal y Ecología, Facultad de Ciencias, Universidad de Granada, Campus de Fuentenueva s/n, 18071 \\ Granada, Spain \\ ${ }^{3}$ Avda. Príncipe de Asturias 30, ático 1; E-08012 Barcelona, Spain
}

Key words. Diptera, Carnidae, Carnus hemapterus, coexistence, diapause, emergence, Hemeromyia, seasonal cycles, temporal and spatial segregation

\begin{abstract}
Seasonal cycles constitute a major challenge for organisms since they may influence the genetic composition of a population, the species structure of a community and the interactions between organisms. Diapause is frequently used by insects to synchronize their life cycle with seasonal changes and is regarded as a key factor in the coexistence of competing species. Here the occurrence, abundance and emergence patterns of three poorly-known species of carnid flies (Carnus hemapterus Nitzsch, 1818, Hemeromyia anthracina Collin, 1949 and Hemeromyia longirostris Carles-Tolrá, 1992), which overwintered in the nests of several bird species at two localities, are reported and evidence of possible interspecific competition sought. Larvae of all three species were found in association with carrion and detritus. Both Hemeromyia species co-occurred in around $50 \%$ of the nests and Carnus with each of the Hemeromyia species at a lower rate (30-40\% of the nests). Coexistence of all three carnid species was rare. We did not find any evidence of interspecific competition in the larval stage. Coexistence did not reduce the number of flies that emerged of any of the three species and the abundance of some species was even positively related. Species-specific emergence patterns and different habitat selection criteria (Carnus hemapterus seemed to avoid nests lined with vegetable material), which diminished the overlap between species were found. Such spatial and temporal segregation could facilitate the coexistence of these closely related species, which have similar ecological requirements, and might influence the seasonal dynamics of this poorly-known assemblage of insects inhabiting the nests of birds.
\end{abstract}

\section{INTRODUCTION}

Seasonal changes in environmental variables (seasonal cycles) constitute a major challenge for organisms (Tauber \& Tauber, 1981) and pose a universal problem for most insects, namely the timing and matching their life cycle to the appropriate season (Jones, 2001). Seasonal cycles also have the potential to influence both the genetic composition of a population and the species structure of a community (e.g., emergence from dormant eggs, Cáceres, 1998 and references therein), and can strongly affect interactions between organisms (e.g., coexistence of competing species, seasonal synchrony between host and parasites). In response to seasonal cycles insects commonly use diapause and quiescence to synchronize their life cycle with the moment when resources are abundant and available (Jones, 2001). Additionally, diapause has been hypothesised in both theoretical and empirical studies to be a key factor in maintaining the coexistence of competing species (Chesson, 1994; Hairston et al., 1996). Therefore, studying seasonal cycles and the related adaptations of a given species or population is basic for understanding how organisms exploit their environment, how they interact and how they evolve (Tauber \& Tauber, 1981). Interspecific comparisons of seasonal cycles and life histories have been particularly fruitful, especially when they involve closely related species that occur together or in adjacent geographic areas (Dearn, 1977; Dingle, 1978; Tauber \& Tauber, 1981) since they can contribute to a better understanding of the evolution of life histories and the comprehension of stable coexistence (Tauber \& Tauber, 1981, 1982). In this paper this approach is used to assess the interspecific relationships of coexisting species of the family Carnidae.

Carnidae is a poorly studied group of acalypterate flies found mainly in the Holarctic Region. It includes parasitic species (genus Carnus Nitzsch, 1818) as well as some non-parasitic ones belonging to the genera Meoneura Rondani, 1856 and Hemeromyia Coquillet, 1902 (Grimaldi, 1997). With the exception of Carnus hemapterus, which has been studied (see, for instance, Capelle \& Whitworth, 1973; Guiguen et al., 1983; Dawson \& Bortolotti, 1997; Roulin, 1998, 1999; Valera et al., 2003, 2004), there is little information on the ecology of Hemeromyia species and it consists mainly of reports on the geographical occurrence of the species (e.g., Papp, 1984, 1998; Carles-Tolrá Hjorth-Andersen, 2002). This is probably due to the fact that finding these species requires specialised sampling of birds nests (Merkl et al., 2004). Here we study the occurrence and seasonal cycle of Carnus hemapterus and two species of Hemeromyia $(H$. 
longirostris and $H$. anthracina) in two separate geographic areas. Since all three species complete their life cycles within birds' nests, and in all cases their larvae feed on the organic material that accumulates in the bottom of the nests (Grimaldi, 1997; Papp, 1998), we hypothesise that coexistence can result in competition among the different species. Therefore, the effects of coexistence of the different species on their relative success were studied, and possible indications of interspecific competition looked for. Since subtle differences in habitat selection and/or differences in the timing of their life cycles may facilitate coexistence, the habitat selection criteria of the three species studied and their seasonal phenologies were studied to check for habitat and/or temporal segregation.

\section{MATERIALS AND METHODS}

\section{Study species}

The life cycle of the species comprise an adult stage, several larval phases and a puparium. Although there is no information on Hemeromyia species, Carnus hemapterus has three larval stages, then diapauses for several months (Guiguen et al., 1983), and adults emerge the following spring. Adult Carnus flies are parasites of nestlings of different bird species, whereas the scarce information on Hemeromyia anthracina and H. longirostris suggests that the adults of these species are saprophagous and feed on faeces and decaying vegetable material (CarlesTolrá, 2001) although they have also been collected on Umbelliferous flowers (Carles-Tolrá, 2004). Therefore, they appear to coexist only in the larval and pupal stage.

\section{Collection of nest material}

Occurrence and emergence time of carnid species was studied by collecting nest material with overwintering pupae from nests of several cavity-nesting bird species. During the second half of July 200227 bee-eater (Merops apiaster) nests from two colonies in central Spain $\left(40^{\circ} 32^{\prime} \mathrm{N}, 03^{\circ} 27^{\prime} \mathrm{W}\right.$, Daganzo, Madrid) were sampled. During the period 17-28 January 2003 samples were also collected in southern Spain from 17 hoopoe (Upupa epops) nests (nine from Guadix, $37^{\circ} 18^{\prime} \mathrm{N}, 3^{\circ} 11^{\prime} \mathrm{W}$, Granada, and eight from Doña María, $37^{\circ} 08^{\prime} \mathrm{N}, 02^{\circ} 43^{\prime} \mathrm{W}$, Almería, $37 \mathrm{~km}$ from the first location), and five roller (Coracias garrulus) and four little owl (Athene noctua) nests in the Desert of Tabernas (Almería, $37^{\circ} 05^{\prime} \mathrm{N}, 2^{\circ} 21^{\prime} \mathrm{W}$ ). On 3 March 2004 five additional roller nests and three little owl nests at Tabernas were sampled. Rollers, bee-eaters and little owls breed in holes dug in sandy cliffs, whereas hoopoes in our study area nest in natural holes in olive trees and piles of stones. Although bee-eaters seldom re-use their nests, rollers and little owls frequently breed in the same hole in successive years.

On 14 January 200426 nest boxes placed on electric masts in Cáceres $\left(39^{\circ} 03^{\prime} \mathrm{N}, 5^{\circ} 14^{\prime} \mathrm{W}\right.$, Extremadura, Western Spain) were sampled. Several species (like the roller, European kestrel Falco tinnunculus, spotless starling Sturnus unicolor and house sparrow Passer domesticus) also breed in these boxes. Whereas it was possible to deduce which boxes were used the previous breeding season, it was not possible to presume by which species. Therefore the type of nest material (rotting material, detritus and faeces forming a solid substrate versus straw, sticks and vegetable material) was classified in a way that might indicate the previous occupant of the nest (rollers and kestrels versus starlings and sparrows, respectively).

Sampling consisted of removing part of the material from the bottom nest using a spoon attached to a stick long enough to reach the nest chamber or by hand (nest boxes). In cases where the nest was composed of vegetable material, the whole structure (i.e., the nest cup) and the earth below the nest were taken. Samples were weighed after the flies had emerged, with the exception of five hoopoe samples that were lost. The amount of nest material collected varied among nests. Nevertheless, the number of flies that emerged from nests for which emergence was recorded was not correlated with the mass of material sampled for any of the species (Spearman rank correlations, $\mathrm{P}>$ 0.15 in all three cases) or for all three species pooled $\left(r_{s}=0.09\right.$, $\mathrm{P}=0.63, \mathrm{n}=28)$. This is also the case both for those nests without vegetable material (Spearman rank correlations, $\mathrm{P}>$ 0.30 in all four cases) and for those with vegetable material but for which only the weight of the earthy substratum was considered (Spearman rank correlations, $\mathrm{P}>0.15$ in all cases).

\section{Emergence patterns of Carnidae}

Emergence patterns are ideally studied in the field. Nevertheless this was not possible since this would necessitate the periodic sampling of nests occupied by birds during the breeding season, which would result in the disturbance of adults and nestlings. Therefore, the emergence of flies was recorded in the laboratory.

After collection, the samples were kept in plastic bags and stored in Almería under ambient conditions in semidarkness, which resembles natural conditions. Observational and experimental data (manipulating temperature during the pupal stage) suggest that, at least for Carnus hemapterus, emergence time is determined by an endogenous annual timing mechanism that can be modified, within certain limits, by temperature (Valera et al., in prep.), as is the case for many insects in temperate climates (Tauber \& Tauber, 1981; Leather et al., 1993). Therefore, our method ensured homogeneous conditions (i.e., the same temperature) for the samples, which is not possible in the field, where the timing or length of use of nests by birds could influence emergence time. It is very unlikely that the three species studied would respond differently to these conditions.

Samples were monitored approximately every three-four days for fly emergence until insect emergence ceased. The study period lasted from 31 January until 8 July 2003 for the samples collected in 2002-2003, from 9 March until 13 July 2004 for those collected in 2004 in Tabernas and from 4 March until 13 July 2004 for samples collected in 2004 in Extremadura. Surveys of the samples collected in 2002-2003 (starting as early as the beginning of February) showed that the earliest emergence of any of the species studied occurred in the first week of March. Therefore, in 2004 (surveys starting on $4^{\text {th }}$ March) only the very first flies to emerge could have been overlooked (see results).

Carnid species were detected in 20 of the 26 nest boxes sampled in western Spain. It was ignored whether the nest boxes sampled were occupied by any bird species. Given that the occurrence of flies may depend on the previous occupation of the nest (at least this is the case for Carnus hemapterus, Roulin, 1998; Valera et al., in prep.), the data is for those 20 nests where at least one species of carnid fly was recorded.

\section{Statistical methods}

Parasite distributions are known to be aggregated, which makes their quantification and comparison difficult (Rózsa et al., 2000). Following Rózsa et al. (2000) prevalence (proportion of infected hosts among all the hosts examined) and mean intensity (number of individuals found in the infected nests) of flies (and the confidence intervals estimated after 4000 replications) were used for quantification purposes. Fisher's exact test was used to compare prevalences and mean intensities were com- 
pared by using bootstrap t-tests (after 2000 replications). ANCOVAS were used to assess the effect of coexistence of the two species on the number of emerging flies of each species after controlling for confounding variables (the abundance of the third species). Logarithmic transformations were used to normalise the data. Nevertheless, since different measures of parasitism may yield different interpretations and answers (Rózsa et al., 2000), the consistency of our results was checked by calculating and comparing median intensities using Mood's median test. Tests are 2 -tailed and $95 \%$ confidence intervals, CI, are provided unless otherwise stated.

Two parameters (total number of flies that emerged per nest at a given time and the moment in time when $50 \%$ of the flies had emerged) were used to describe the temporal overlap among species since each index has different biases. Whereas the number of individuals may overstate those nests with many flies, working with percentages may inflate the importance of early or late emergence of some flies in nests with few individuals.

Statistical tests were done using the program Quantitative Parasitology 2.0 (Reiczigel \& Rózsa, 2001) and the STATISTICA 6.0 package (StatSoft, Inc. 2001).

\section{RESULTS}

\section{Occurrence and abundance of carnid species}

Three species of carnid flies emerged from the nests sampled: the ectoparasite Carnus hemapterus, and the non-parasitic Hemeromyia anthracina and Hemeromyia longirostris.

Carnus hemapterus was detected in $90.0 \%(9 / 10)$ of the roller nests, $85.7 \%(6 / 7)$ of the little owl nests, $70.6 \%$ $(12 / 17)$ of the hoopoe nests and $37.0 \%(10 / 27)$ of the beeeater nests. Carnus flies were also recorded in 8 out of 20 (40\%) nest boxes sampled in Western Spain. In contrast, Hemeromyia flies were found only in hoopoe nests and nest boxes in western Spain.

Concerning hoopoe nests, both Hemeromyia anthracina and $H$. longirostris were detected in 7 (41.2\%) out of 17 nests. Overall, $23 \mathrm{H}$. anthracina and $159 \mathrm{H}$. longirostris (115 flies emerged from a single nest) were collected. There were no differences in the mean number of $H$. anthracina $(3.3, \mathrm{CI}: 1.3-6.4)$ and $H$. longirostris flies (22.7, CI: 4.4-71.0) per infested nest (Bootstrap 2-sample t-test: $\mathrm{t}=1.2, \mathrm{P}=0.40)$. Prevalence of $C$. hemapterus $(70.6 \%)$ did not differ from that of either $H$. anthracina or H. longirostris (Fisher's exact test, $\mathrm{P}=0.16$ in both comparisons). The mean number of Carnus flies per infested nest (17.0, CI: 5.33-39.2) was not significantly different from that of $H$. anthracina $(\mathrm{t}=1.65, \mathrm{P}=$ $0.16)$ or $H$. longirostris $(\mathrm{t}=0.32, \mathrm{P}=0.76)$.

Regarding nest boxes, a total of 163 Hemeromyia anthracina flies were found in $16(80.0 \%)$ out of 20 nest boxes and $237 \mathrm{H}$. longirostris flies emerged from 17 $(85.0 \%)$ out of 20 boxes. The mean number of both Hemeromyia species in infected nests did not differ significantly $(H$. anthracina: $10.2, \mathrm{CI}$ : $5.3-21.5 ;$ H. longirostris: $13.9, \mathrm{CI}: 8.2-24.2, \mathrm{t}=0.67, \mathrm{P}=0.50)$. Prevalences of $H$. anthracina and $H$. longirostris were both significantly higher than that for $C$. hemapterus $(40.0 \%)$ (Fisher's exact test, $\mathrm{P}=0.02$ and 0.008 respectively) but the mean intensity of Carnus flies (18.2, CI: 7.4-34.2)

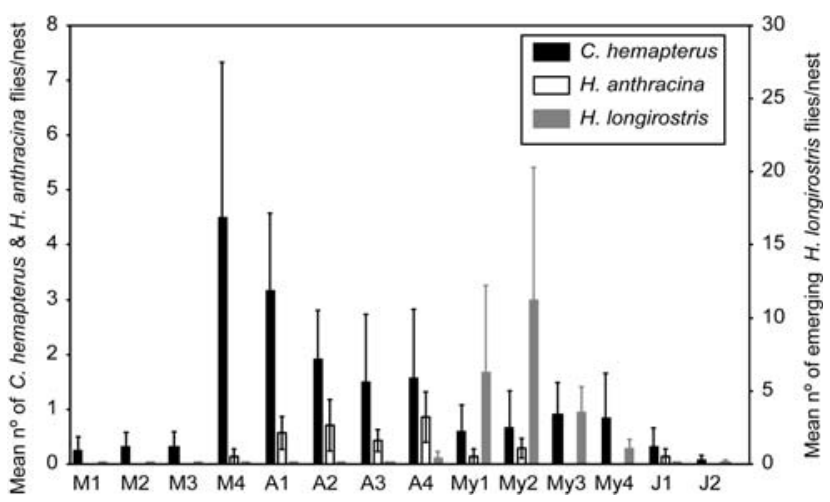

Fig. 1. Phenology of emergence of Carnus hemapterus, Hemeromyia anthracina and H. longirostris in 2003 from hoopoe nests located in southeastern Spain (see Methods for sample size). Mean values ( \pm SEM) of flies per nest are shown.

did not differ from that for both $H$. anthracina and $H$. longirostris $(\mathrm{t}=0.97, \mathrm{P}=0.33$ and $\mathrm{t}=0.51, \mathrm{P}=0.62$, respectively).

\section{Patterns of emergence and temporal segregation}

Data from hoopoe nests as well as that from nest boxes show that the pattern of emergence of the three species of diptera differs (Figs 1 and 2).

Carnus flies from hoopoe nests had a long emergence period (Fig. 1) that started at the beginning of March, peaked at the end of this month and lasted until mid June. Emergence of $H$. anthracina flies started at the end of March, when $31.9 \%$ of the Carnus hemapterus flies had already emerged, and showed several peaks. The emergence period of $H$. longirostris lasts for only one month, with a clear peak around mid May and is delayed relative to the other species. The first $H$. longirostris flies emerged at the end of April, when $79.9 \%$ of the Carnus flies and $82.6 \%$ of the $H$. anthracina had already emerged (Fig. 1). The moment in time when $50 \%$ of the flies have emerged differs among the species (ANOVA: $F_{2,23}=14.7$, $\mathrm{P}<0.001)$.

These patterns parallel those found in nest boxes (Fig. 2). Although the earliest Carnus flies to emerge were probably missed, the shape of the curve of emergence suggests that $C$. hemapterus starts emerging earlier than $H$. anthracina. Hemeromyia longirostris is again the species with the shortest and most delayed emergence period (Fig. 2), as at least $86.3 \%$ of the Carnus flies and $46.6 \%$ of the $H$. anthracina flies had emerged by the end of March, when the first $H$. longirostris appeared. The absence of a significant difference in the time when $50 \%$ of each species had emerged (ANOVA: $\mathrm{F}_{2,38}=0.95, \mathrm{P}=$ 0.39 ) is probably partly due to the fact that the earliest Carnus flies to emerge were missed.

A comparison of Figs 1 and 2 suggests some degree of geographic variation in the emergence of the three species studied. All the $H$. longirostris had emerged in western Spain by the time they started emerging from hoopoe nests in southern Spain. Forty six percent of the $H$. anthracina had emerged in western Spain by the time the first fly of this species was recorded from hoopoe nests 


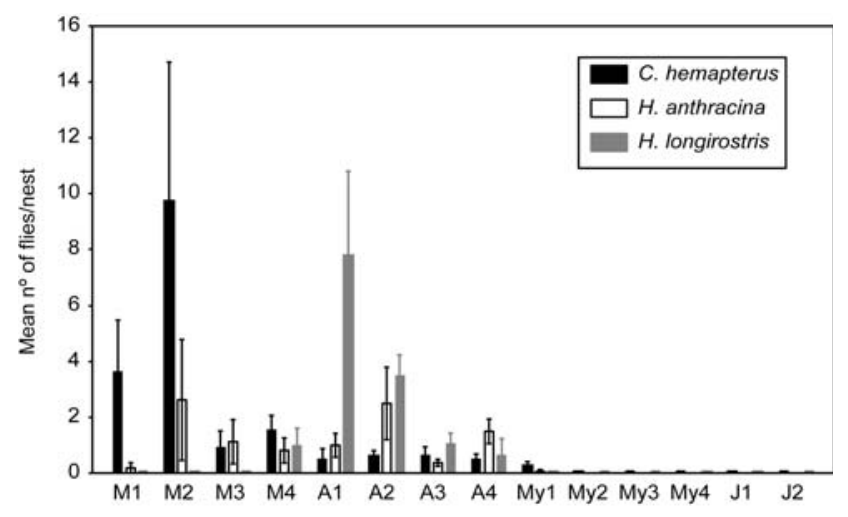

Fig. 2. Phenology of emergence of Carnus hemapterus, Hemeromyia anthracina and $H$. longirostris in 2004 from nest boxes in western Spain (see Methods for sample size). Mean values $( \pm$ SEM) of flies per nest are shown.

and the peak of $C$. hemapterus emergence seemingly occurred 2 weeks earlier in western than in southern Spain.

\section{Coexistence and interspecific competition}

Both Hemeromyia species co-occurred in four out of 17 hoopoe nests and in 13 out of 20 nest boxes. Coexistence of both species did not influence either of them, since the number of $H$. anthracina flies emerging when the species coexisted did not differ from that recorded for nests from which only this Hemeromyia species emerged (after controlling for the abundance of Carnus flies) (ANCOVA: $\mathrm{F}_{1,20}=1.80, \mathrm{P}=0.19$, covariate: $\mathrm{F}_{1,20}=2.73, \mathrm{P}=0.11$, Fig. 3a). The result was the same for $H$. longirostris (ANCOVA: $\mathrm{F}_{1,21}=0.40, \mathrm{P}=0.53$, covariate: $\mathrm{F}_{1,21}=0.98, \mathrm{P}$ $=0.33$, Fig. 3a).

Carnus hemapterus and $H$. anthracina were both present in 13 nests (six out of 17 hoopoe nests and seven out of 20 nest boxes). There were no differences in the number of Carnus flies that emerged whether it coexisted or not with $H$. anthracina (controlling for the occurrence of $H$. longirostris, ANCOVA: $\mathrm{F}_{1,17}=0.91, \mathrm{P}=0.35$, covariate: $F_{1,17}=8.63, P=0.009$, Fig. $3 b$ ). In contrast, the mean number of $H$. anthracina that emerged was significantly higher when it coexisted with Carnus than when it did not $\left(\mathrm{F}_{1,19}=11.96, \mathrm{P}=0.003\right.$, Fig. $\left.3 \mathrm{~b}\right)$, although the abundance of $H$. longirostris was significantly correlated with the abundance of Carnus (covariate: $\mathrm{F}_{1,19}=22.6, \mathrm{P}=$ 0.0001). Nevertheless, the median value for $H$. anthracina flies did not differ in nests with and without Carnus flies (Mood's median test, $\mathrm{P}=0.41$, Fig. $3 \mathrm{~b}$ ).

Carnus hemapterus and $H$. longirostris coexisted in 11 nests (six out of 17 hoopoe nests and five out of 20 nest boxes). Emergence of Carnus flies from nests with and without $H$. longirostris did not vary (controlling for the occurrence of $H$. anthracina, ANCOVA: $\mathrm{F}_{1,17}=1.26, \mathrm{P}=$ 0.27 , covariate: $\mathrm{F}_{1,17}=0.28, \mathrm{P}=0.59$, Fig. $3 \mathrm{c}$ ). This was also the case for $H$. longirostris that coexisted or not with Carnus (ANCOVA: $\mathrm{F}_{1,21}=1.19, \mathrm{P}=0.28$, covariate: $\mathrm{F}_{1,21}$ $=3.33, \mathrm{P}=0.08$, Fig. $3 \mathrm{c})$.
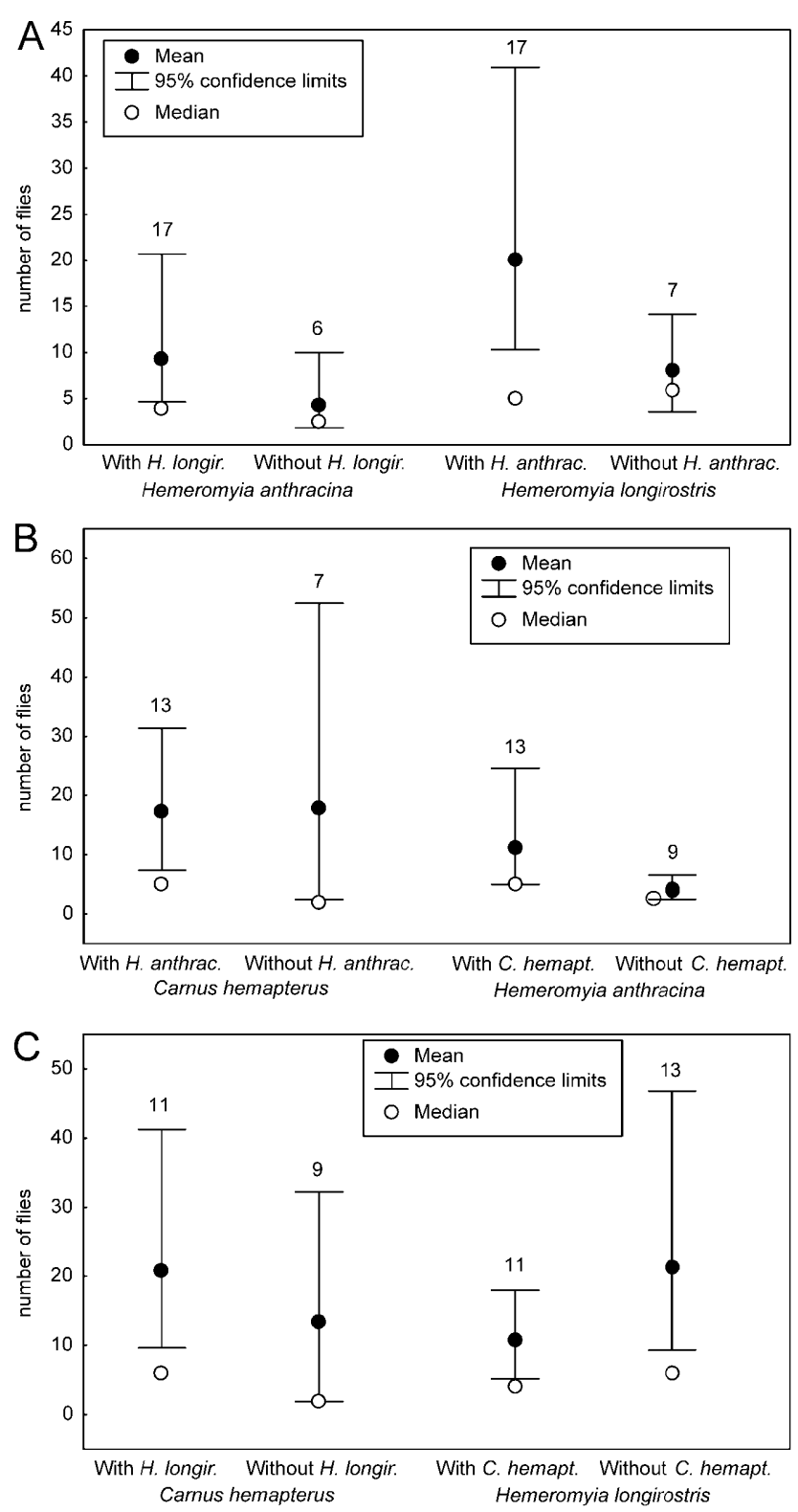

Fig. 3. Mean (and 95\% confidence limits after 4000 replications) and median number of flies that emerged from nests where they did and did not coexist with one another: A Hemeromyia anthracina and $H$. longirostris; B - Carnus hemapterus and Hemeromyia anthracina; $\mathrm{C}$ - Carnus hemapterus and Hemeromyia longirostris. Figures show the number of nests in each category.

Abundance of $H$. anthracina and $H$. longirostris in nests where they coexisted was marginally associated after controlling for the abundance of Carnus flies (partial correlation, $\mathrm{r}=0.44, \mathrm{P}=0.088, \mathrm{n}=17$ ). Similarly, the number of Carnus flies correlated positively with the number of $H$. longirostris in the nests where they coexisted (partial correlation, $\mathrm{r}=0.76, \mathrm{P}=0.011, \mathrm{n}=11$ ). In contrast, there was no association between the abundance of Carnus and $H$. anthracina flies in those nests where they coexisted (partial correlation, $\mathrm{r}=-0.20, \mathrm{P}=0.52, \mathrm{n}$ $=13)$. 
TABLE 1. Relationship between occurrence of three species and type of substratum (vegetable $-\mathrm{n}=6$ nests; earthy $-\mathrm{n}=14$ nests) in nest boxes. Number of nests where Carnus hemapterus, Hemeromyia anthracina and $H$. longirostris were found and the percentages (in brackets) in which each species was recorded.

\begin{tabular}{lcc}
\hline & $\begin{array}{c}\text { Vegetable } \\
\text { substratum }\end{array}$ & $\begin{array}{c}\text { Earthy } \\
\text { substratum }\end{array}$ \\
\hline Carnus hemapterus & $0(0.0 \%)$ & $8(100.0 \%)$ \\
Hemeromyia anthracina & $4(25.0 \%)$ & $12(75.0 \%)$ \\
Hemeromyia longirostris & $6(35.3 \%)$ & $11(64.7 \%)$ \\
\hline
\end{tabular}

All three carnid species co-occurred in only 3 hoopoe nests and in 4 nest boxes.

\section{Habitat preferences and spatial segregation}

Hemeromyia flies were found only in hoopoe nests and nest boxes, whereas $C$. hemapterus flies were recorded in natural nests of all the species studied as well as in eight out of 20 nest boxes. The occurrence of C. hemapterus is significantly associated with the type of substratum in the nest box (Fisher's exact test, $\mathrm{P}=0.042$ ); all nests in which $C$. hemapterus was found had earthy rotting material and no Carnus fly emerged from nests lined with straw and vegetable matter (Table 1). In contrast, the occurrence of $H$. anthracina and $H$. longirostris was independent of the type of substratum in the nest box (Fisher's exact test, $\mathrm{P}>0.1$ for both species).

\section{DISCUSSION}

This study, to our knowledge, provides the first information on the ecology of two Hemeromyia species, shows that three closely related carnid species with ecologically similar larval and pupal stages can coexist and reveals clear differences in the life-history patterns of these species.

\section{Coexistence of carnid species and interspecific competition}

Although the larval stages of all three diptera are found in association with carrion and the excrement of birds (Grimaldi, 1997), coexistence is infrequent. Despite both Hemeromyia species co-occurring relatively frequently (around $50 \%$ of nests), and Carnus co-occurring with each of the Hemeromyia species at only a slightly lower frequency (around $30-40 \%$ of nests), coexistence of all three carnid species was recorded for only seven out of 34 nests where any of the species was registered. Moreover, the differences in their seasonal cycles may facilitate coexistence by means of temporal segregation.

Coexistence here refers to the larval and pupal stages, therefore, interspecific competition for resources could occur in the larval phase. However, our results do not reveal any evidence of interspecific competition. For the two closely related Hemeromyia species, which showed the highest incidence of coexistence, the numbers of flies that emerged when they co-occurred and did not were similar. Assuming that the overlap in the emergence pattern of flies reflects a similar pattern of occurrence of larvae (this is likely if the species spend a similar time in diapause), then a high degree of competition between Carnus and H. anthracina would be expected (the pair of species with the greatest degree of overlap in time of emergence). However, our results do not confirm this prediction. The number of Carnus flies that emerged is not affected by the presence of $H$. anthracina and the effect of the former on $H$. anthracina is, if anything, positive. In fact, the only associations found in this study are positive (a slight positive relationship between the numbers of $H$. anthracina and $H$. longirostris flies that emerged and a stronger one between those of $C$. hemapterus and $H$. longirostris). Thus, coexistence in this system did not seem to result in interspecific competition, but in neutral or slightly positive associations. Although, it is unlikely the positive associations were a result of differences in the amount of nest material (given the absence of a correlation between the number of flies that emerged per nest and amount of nest material - see methods), some qualitative factor, like the conditions for larval development, could account for the positive correlations found in this study. A better method would be to raise fly larvae and establish their growth rates in standardised media in the absence and presence of their putative competitors, but more basic knowledge about the biology of these species is needed before this can be successfully done.

\section{Limitation of interspecific competition by spatial and temporal segregation}

Several factors may limit competition and facilitate the coexistence of these closely related species, namely different habitat selection criteria resulting in spatial segregation, and different life cycles resulting in temporal segregation. Even though the larvae of all three species inhabit a specialised habitat there seems to be interspecific differences in habitat selection criteria. Carnus hemapterus seemed to avoid nests lined with vegetable matter and was common in nests with a sandy substratum (e.g., little owls, rollers and bee-eaters) in which Hemeromyia flies did not occur. Co-occurrence of Carnus flies with both Hemeromyia species was therefore restricted to hoopoe nests (that have an earthy substratum formed of wood shavings, excrement and prey remains), that seem to be good enough for $C$. hemapterus, and to artificial nest-boxes with a substratum suitable for both Hemeromyia species. Preference of $C$. hemapterus for specific hosts with particular types of nest has been already reported. Guiguen et al. (1983) described the preference of Carnus for a host species in a multispecific colony of birds and argued that such specificity could be determined by the type of nest although they could not ascertain the causal factor. Our data suggest that $C$. hemapterus rejects nests with abundance of vegetable matter since no flies emerged from these nests despite their probably being nests of bird species reported to be hosts of this parasitic fly (e.g., Sturnus and Passer spp., see Grimaldi, 1997). This agrees with the low prevalence and infestation intensity of $C$. hemapterus found by Westneat et al. (2004) in a colony of house sparrows (Passer domesticus). In contrast, Liker et al. (2001) found a high prevalence and abundance of these flies in a colony of 
starlings (Sturnus vulgaris). Valera et al. (unpubl. data) found that the number of flies emerging from nests used the previous season by bee-eaters was significantly higher than from bee-eater nests re-used the previous season by rock sparrows (Petronia petronia). Thus, the type of nest could be more important for the larval-pupal stage than the adult stage. Concerning Hemeromyia spp., more information about their occurrence is needed before drawing any conclusions about their habitat preferences.

Our results also reveal distinctive and consistent temporal patterns in the emergence of each species at both study sites. The emergence of $C$. hemapterus precedes that of $H$. anthracina, whereas $H$. longirostris emerges last and overlaps little with the two other species. The occurrence of Carnus seems to be determined by its parasitic nature since several authors (Liker et al., 2001; Valera et al., 2003) report a synchronization between the emergence of Carnus flies and the hatching of their nestling hosts. Whereas the factors (i.e., resources) accounting for the emergence patterns of both Hemeromyia species are unknown, the limited temporal overlap in the emergence of $H$. anthracina and $H$. longirostris could have evolved as a way to reduce interspecific competition during the adult stage. Temporal segregation of adult emergence may also result in segregation at the larval stage, therefore diminishing competition between larvae. However, with our current knowledge, this cannot be assumed. In line with this it is remarkable that positive associations were found between all pairs of species except for the two that most overlapped in their emergence pattern (Carnus hemapterus and H. anthracina).

The variation in life-history patterns that allows closely related species to co-exist has been an important theme in ecology for decades. Diapause has been hypothesised, in both theoretical and empirical studies, to be important in the coexistence of competing species. Several studies show that differences in a key life-history trait like diapause among species that share the same spatial habitat facilitate coexistence (Santer et al., 2000; Frisch, 2001; Tomiuk et al., 2004). Thus, differences in diapause length and/or timing of diapause might have resulted in the different emergence patterns of the Hemeromyia species that, in turn, might diminish interspecific competition and facilitate coexistence. Unfortunately the lack of information on natural history, feeding habits and cues required to terminate dormancy for these species makes addressing the interspecific variance in the time of emergence of Hemeromyia adults pure speculation. Regardless of the mechanism involved, our results show an obvious seasonal succession of species with a marked increase and decrease in abundance that could play an important role in the seasonal dynamics of the assemblage of insects inhabiting nests of birds (see, for instance, Hairston et al., 2000 for a similar scenario).

ACKNOWLEDGEMENTS. We thank H. Hoi, L. Rózsa and two anonymous reviewers for helpful comments and the editorial staff for improving wording. J. Avilés and D. Parejo made available nest boxes in Extremadura and provided logistic support. The Consejería de Medio Ambiente (Junta de Andalucía) and the Comunidad de Madrid kindly allowed us to sample nests of different bird species. FVH was supported by the Programa de Ayudas para el Retorno de Investigadores de la Consejería de Educación y Ciencia (Junta de Andalucía) and MMV by the Spanish Ministerio de Educación, Cultura y Deporte (Programa de Becas Postdoctorales en España y en el Extranjero), and Ministerio de Ciencia y Tecnología (project BOS2002-01082).

\section{REFERENCES}

CÁCERES C.A. 1998: Interspecific variation in the abundance, production and emergence of Daphnia diapausing eggs. Ecology 79: 1699-1710.

CApelle K.J. \& Whitworth T.L. 1973: The distribution and avian hosts of Carnus hemapterus (Diptera: Milichiidae) in North America. J. Med. Entomol. 10: 525-526.

Carles-Tolrá M. 2001: Datos taxonómicos y ecológicos de 304 especies de dípteros acalípteros (Diptera, Acalyptrata). Bol. Soc. Entomol. Aragon. 28: 89-103.

Carles-Tolrá M. 2004: Dípteros nuevos para la Península Ibérica capturados en la provincia de Salamanca (España) (Insecta, Diptera). Bol. Soc. Entomol. Aragon. 35: 187-194.

Carles-Tolrá Huorth-Andersen M. 2002: Catálogo de los Diptera de España, Portugal y Andorra (Insecta). Monografías de la Sociedad Entomológica Aragonesa, 8. Zaragoza, 323 pp.

CHesson P. 1994: Multispecies competition in variable environments. Theor. Popul. Biol. 45: 227-276.

DEARN J.M. 1977: Variable life history characteristics along an altitudinal gradient in three species of Australian grasshopper. Oecologia 28: 67-85.

Dawson R.D. \& Bortolotti G.R. 1997: Ecology of parasitism of nestling American Kestrels by Carnus hemapterus (Diptera, Carnidae). Can. J. Zool. 75: 2021-2026.

Dingle H. (ed.) 1978: Evolution of Insect Migration and Diapause. Springer, New York/Heidelberg/Berlin, 284 pp.

FrISCH D. 2001: Life cycles of the two freshwater copepods Cyclops strenuus Fischer and Cyclops insignis Claus (Cyclopoida, Copepoda) in an amphibious floodplain habitat. Hydrobiologia 453: 285-293.

GRIMALDI D. 1997: The bird flies, genus Carnus: species revision, generic relationships and a fossil Meoneura in amber (Diptera: Carnidae). Am. Mus. Nov. $n^{\circ}$ 3190. American Museum of Natural History, New York, $30 \mathrm{pp}$.

Guiguen C., Launay H. \& Beaucournu J.C. 1983: Ectoparasites des oiseaux en Bretagne. I. Répartition et écologie d'un diptère hematophage nouveau pour la France: Carnus hemapterus Nitzsch. Rev. Fr. Entomol. 5: 54-62.

Hairston N.G. JR., Ellner S. \& Kearns C.M. 1996: Overlapping generations: the storage effect and the maintenance of biotic diversity. In Rhodes O.E. Jr., Chesser R.K. \& Smith M.H. (eds): Population Dynamics in Ecological Space and Time. Univ. Chicago Press, Chicago, pp. 109-145.

Hairston N.G. JR, Hansen A.M. \& Schaffner W.R. 2000:. The effect of diapause emergence on the seasonal dynamics of a zooplankton assemblage. Freshwater Biol. 45: 133-145.

JONES R. 2001: Mechanisms for locating resources in space and time: impacts on the abundance of insect herbivores. Austral. Ecol. 26: 518-524.

Leather S.R., Walters K.F.A. \& Bale J.S. 1993: The Ecology of Insect Overwintering. Cambridge University Press, Cambridge, UK, $255 \mathrm{pp}$.

Liker A., Márkus M., Vozár A., Zemankovics E. \& Rózsa L. 2001: Distribution of Carnus hemapterus in a starling colony. Can. J. Zool. 79: 574-580. 
Merkl O., Bagyura J. \& Rózsa L. 2004: Insects inhabiting Saker (Falco cherrug) nests in Hungary. Ornis Hung. 14: 1-4.

PApp L. 1984: Family Carnidae. In Soós A. \& Papp L. (eds): Catalogue of Palearctic Diptera. Vol 10. Clusidae - Chloropidae. Akademiai Kiadó, Budapest, pp. 118-124.

PApp L. 1998: Family Carnidae. In Papp L. \& Darvas B. (eds): Manual of Palaearctic Diptera. Vol. 3. Higher Brachycera. Science Herald, Budapest, pp. 211-217.

Reiczigel J. \& Rózsa L. 2001: Quantitative Parasitology 2.0. Szent István University, Budapest.

Rózsa L., Reiczigel J. \& Majoros G. 2000: Quantifying parasites in samples of hosts. J. Parasitol. 86: 228-232.

Roulin A. 1998: Cycle de reproduction et abondance du diptère parasite Carnus hemapterus dans les nichées de chouettes effraies Tyto alba. Alauda 66: 265-272.

Roulin A. 1999: Fécondité de la mouche Carnus hemapterus, ectoparasite des jeunes chouettes effraies Tyto alba. Alauda 67: 205-212.

Santer B., Blohm-Sievers E., Cáceres C.E. \& Hairston N.G. 2000: Life-history variation in the coexisting freshwater copepods Eudiaptomus gracilis and Eudiaptomus graciloides. Archiv Hydrobiol. 149: 441-458.
StatSoft Inc. 2001: STATISTICA for Windows. StatSoft, Inc.,Tulsa, OK.

TAuber C.A. \& TAuber M.J. 1981: Insect seasonal cycles: genetics and evolution. Annu. Rev. Ecol. Syst. 12: 281-308.

TAUber C.A. \& TAuber M.J. 1982: Evolution of seasonal adaptations and life history traits in Chrysopa: response to diverse selective pressures. In Dingle H. \& Hegmann J.P. (eds): Evolution and Genetics of Life Histories. Springer Verlag, New York, pp. 51-72.

Tomiuk J., NikLasson M. \& Parker E.D. 2004: Maintenance of clonal diversity in Dipsa bifurcata (Fallen, 1810) (Diptera: Lonchopteridae). II. Heredity 93: 72-77.

Valera F., Casas-Crivillé A. \& HoI H. 2003: Interspecific parasite exchange in a mixed colony of birds. J. Parasitol. 89: 245-250.

Valera F., Hoi H., Darolová A. \& Krištofík J. 2004: Size vs. health as a cue for host choice: a test of the Tasty Chick Hypothesis. Parasitology 129: 59-68.

Westneat D.F., Weiskittle J., Edenfield R., Kinnard T.B. \& Poston J.P. 2004: Correlates of cell-mediated immunity in nestling house sparrows. Oecologia 141: 17-23.

Received July 1, 2005; revised and accepted October 10, 2005 